- Oral cancer is increasing.

- Tobacco and alcohol are the most common aetiological factors.

- Surgery and radiotherapy are the main treatments.

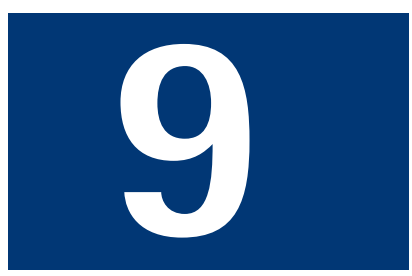

\title{
Oral Medicine - Update for the dental practitioner Oral cancer
}

\author{
C. Scully ${ }^{1}$ and D. H. Felix ${ }^{2}$
}

This series provides an overview of current thinking in the more relevant areas of oral medicine for primary care practitioners, written by the authors while they were holding the Presidencies of the European Association for Oral Medicine and the British Society for Oral Medicine, respectively. A book containing additional material will be published. The series gives the detail necessary to assist the primary dental clinical team caring for patients with oral complaints that may be seen in general dental practice. Space precludes inclusion of illustrations of uncommon or rare disorders, or discussion of disorders affecting the hard tissues. Approaching the subject mainly by the symptomatic approach - as it largely relates to the presenting complaint - was considered to be a more helpful approach for GDPs rather than taking a diagnostic category approach. The clinical aspects of the relevant disorders are discussed, including a brief overview of the aetiology, detail on the clinical features and how the diagnosis is made. Guidance on management and when to refer is also provided, along with relevant websites which offer further detail.

\section{ORAL MEDICINE}

1. Aphthous and other common ulcers

2. Mouth ulcers of more serious connotation

3. Dry mouth and disorders of salivation

4. Oral malodour

5. Oral white patches

6. Oral red and hyperpigmented patches

7. Orofacial sensation and movement

8. Orofacial swellings and lumps

\section{Oral cancer}

10. Orofacial pain

"Professor, Consultant, Dean, Eastman Dental Institute for Oral Health Care Sciences, 256 Gray's Inn Road, UCL, University of London, London WC1X 8LD ${ }^{2}$ Consultant, Senior Lecturer, Glasgow Dental Hospital and School, 378 Sauchiehall Street, Glasgow G2 3JZ |

Associate Dean for Postgraduate Dental Education, NHS Education for Scotland, 2nd Floor, Hanover Buildings, 66 Rose Street, Edinburgh EH2 2NN

${ }^{*}$ Correspondence to: Professor Crispian Scully CBE

Email:c.scully@eastman.ucl.ac.uk

\section{Refereed Paper}

( ) British Dental Journal 2006; 200

13-17

\section{ORAL CANCER}

Oral cancer is the most common malignant epithelial neoplasm affecting the mouth. More than $90 \%$ is oral squamous cell carcinoma (OSCC) (Table 1).

\section{Table 1 Oral malignant neoplasms}

\section{Common}

Oral squamous cell carcinoma

Cancers of the oral cavity are classified according to site:

- lip (International Classification of Diseases (ICD) 140),

- tongue (ICD 141)

- gum (ICD 143),

- floor of the mouth (ICD 144) and

- unspecified parts of the mouth (ICD 145)

Less common

- Kaposi's sarcoma

- Lymphoma

- Malignant melanoma

- Maxillary antral carcinoma (or other neoplasms)

- Metastatic neoplasms (breast, lung, kidney, stomach, liver)

- Neoplasms of bone and connective tissue

Odontogenic tumours

Salivary gland tumours

Oral squamous cell carcinoma (OSCC) is among the 10 most common cancers worldwide. The mortality rate in the UK is just over 50\%, despite treatment, with about 1,700 deaths per year, mainly because of late detection. The number of new mouth (oral) and oropharyngeal cancers is currently estimated to be 300,000 cases worldwide, amounting to around 3\% of total cancers. In the UK, the total number of recorded cases of oral cancer is about 4,500, with around 1,700 deaths, and the incidence appears to be rising in the UK and many other countries. In the UK, there was a 17\% increase in cases of oral cancer from 3,673 in 1995 to 4,304 in 1999. Scotland has about double the incidence rate of oral cancer compared with England.

OSCC is seen predominantly in males but the male:female differential is decreasing. OSCC is seen predominantly in the elderly but is increasing in younger adults.

\section{POTENTIALLY MALIGNANT STATES}

Some potentially malignant (precancerous) lesions which can progress to OSCC include the following (Table 2):

- Erythroplasia (erythroplakia; see article 6)

- this is the lesion most likely to progress to

carcinoma, and is very dangerous.

- Leukoplakias (See article 5), particularly:

- Nodular leukoplakia

- Speckled leukoplakia

- Proliferative verrucous leukoplakia

- Sublingual leukoplakia

- Candidal leukoplakia

- Syphilitic leukoplakia.

Some other potentially malignant (precancerous) conditions include: 
- Actinic cheilitis (mainly seen on the lower lip)

- Lichen planus (mainly the non-reticular or erosive type)

- Submucous fibrosis (seen in users of areca nut)

- Rarities such as:

- Dyskeratosis congenita

- Discoid lupus erythematosus

- Paterson-Kelly syndrome (sideropenic dysphagia; Plummer-Vinson syndrome).

\begin{tabular}{lll}
\multicolumn{3}{l}{ Table 2 Potentially malignant oral lesions } \\
\hline Lesion & Aetiology & Features \\
\hline Erythroplasia & Tobacco/alcohol & Flat red plaque \\
Leukoplakia & Tobacco/alcohol & White or speckled plaque \\
Proliferative verrucous leukoplakia & $\begin{array}{l}\text { Tobacco/alcohol/human } \\
\text { papillomavirus (HPV) }\end{array}$ & White or speckled or nodular plaque \\
Sublingual keratosis & Tobacco/alcohol & White plaque \\
Actinic cheilitis & Sunlight & White plaque/erosions \\
Lichen planus & Idiopathic & White plaque/erosions/red lesions \\
Submucous fibrosis & Areca nut & Immobile mucosa \\
Discoid lupus erythematosus & Idiopathic & White plaque/erosions/red lesions \\
Chronic candidosis & Candida albicans & White or speckled plaque \\
Syphilitic leukoplakia & Syphilis & White plaque \\
Atypia in immunocompromised & HPV & White or speckled plaque \\
patients & & \\
Dyskeratosis congenita & Genetic & White plaques \\
$\begin{array}{l}\text { Paterson-Kelly syndrome } \\
\text { (sideropenic dysphagia; }\end{array}$ & Iron deficiency & Post-cricoid web \\
Plummer-Vinson syndrome) & &
\end{tabular}

PREDISPOSING FACTORS (RISK FACTORS)

OSCC is most common in older males, in lower socioeconomic groups and in ethnic minority groups.

OSCC arises because of damage to DNA (mutations) which can arise spontaneously - probably because of free radical damage, or can be caused by chemical mutagens (carcinogens), ionising radiation or micro-organisms. OSCC arises as a consequence of multiple molecular events causing genetic damage affecting many chromosomes and genes, and leading to DNA changes. The accumulation of genetic changes leads to cell dysregulation to the extent that growth becomes autonomous and invasive mechanisms develop - this is carcinoma (Fig. 1).
Actinic radiation may predispose to lip cancer but the hazards from other types of radiation are unclear.

Intraoral squamous cell carcinoma (SCC) is seen especially in relation to various lifestyle habits. These are mainly tobacco and alcohol related.

Tobacco, whether smoked or chewed, releases a complex mixture of at least 50 compounds including polycyclic aromatic hydrocarbons such as benzpyrene, nitrosamines, aldehydes and aromatic amines which are carcinogens.

Alcohol (ethanol) is metabolised to acetaldehyde, which may be carcinogenic. Nitrosamine and urethane contaminants may also be found in some alcoholic drinks. Alcohol damage to the liver might, by impairing carcinogen metabolism, also play a role.

The combination of tobacco use and alcohol consumption is particularly implicated in OSCC.

Betel quid, often containing betel vine leaf, betel (areca) nut, catechu, and slaked lime together with tobacco, and appears to be carcinogenic. Some 20\% of the world's population use betel. In persons from the developing world, OSCC is seen especially in tobacco or alcohol users and particularly in betel quid users. Various other chewing habits, usually containing tobacco, are used in different cultures (eg Qat. Shammah. Toombak).

\section{OTHER FACTORS}

Not all tobacco/alcohol users develop cancer, and similarly not all patients with cancer have these habits, and thus other factors must also play a part. These may include:

- Deficiencies of vitamins A, E or C or possibly trace elements

- An impaired ability to metabolise carcinogens

- An impaired ability to repair DNA damaged by mutagens

- Immune defects. These may predispose to OSCC, especially lip cancer, which is increased in, eg immunosuppressed organ transplant recipients.

\section{CLINICAL FEATURES}

Most oral cancer is carcinoma on the lower lip where it may be preceded by, or associated with, actinic cheilitis (Fig. 2) induced by chronic exposure to sunlight, and typically presents as a swelling or lump (Fig. 3 ). The other main site is intraorally, especially on the postero-lateral border/ventrum of the tongue (Fig. 4).

Intraoral SCC may present as an indurated lump/ulcer ie a firm infiltration beneath the mucosa (Figs 5-6); a lump sometimes with abnormal supplying blood vessels; a red lesion (erythroplasia); a granular ulcer with fissuring or raised exophytic margins; a white or mixed white and red lesion (Fig. 7); a white lesion (Fig. 8), a non-healing extraction socket; a lesion fixed to deeper tissues or to overlying skin or mucosa; or cervical lymph node enlargement, especially if there is hardness in a lymph node or fixation. SCC should be considered where any of these features persist for more than three weeks (Fig. 9). 


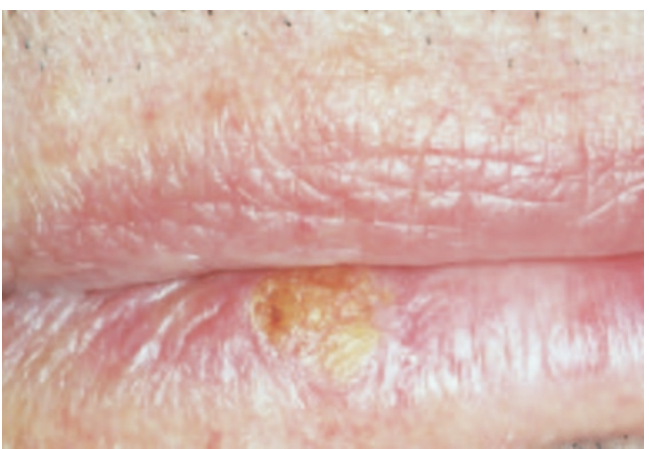

Fig. 2 Actinic keratosis

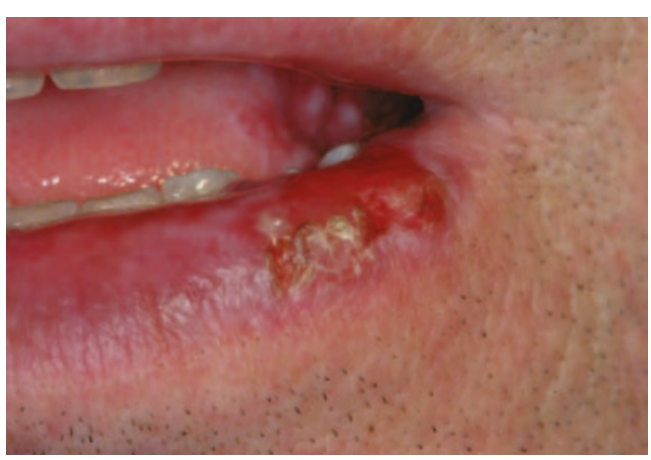

Fig. 3 Early squamous carcinoma of the lip

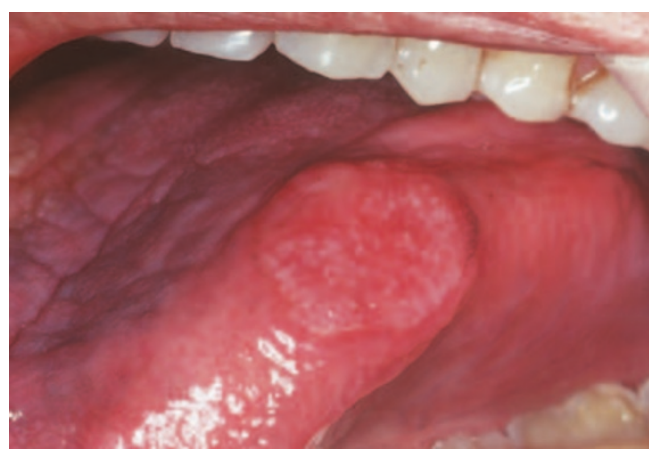

Fig. 4 SCC tongue

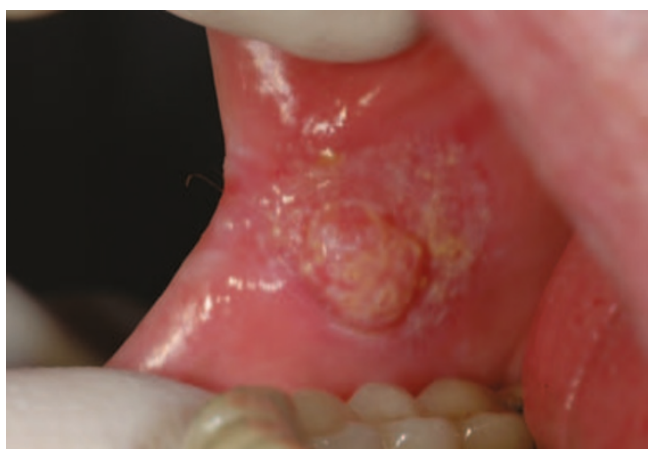

Fig. 5 SCC buccal mucosa

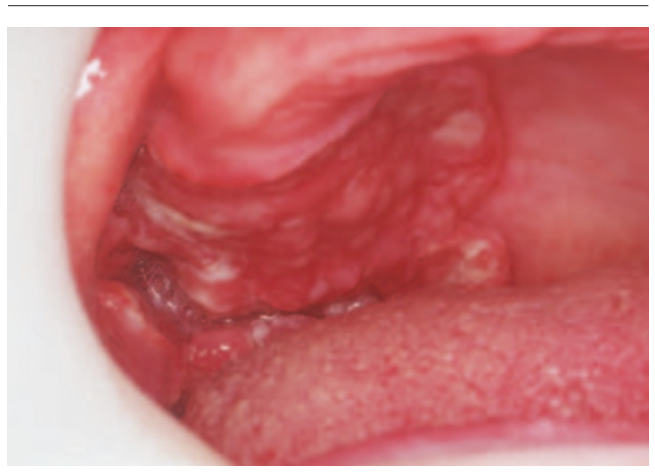

Fig. 6 SCC in soft palate complex

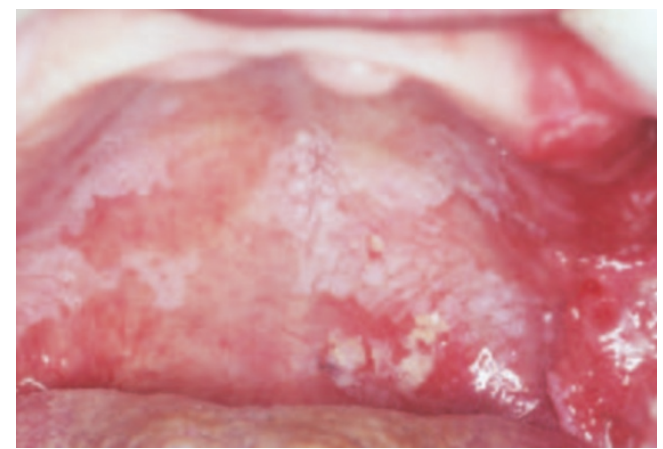

Fig. 7 SCC arising in leukoplakia

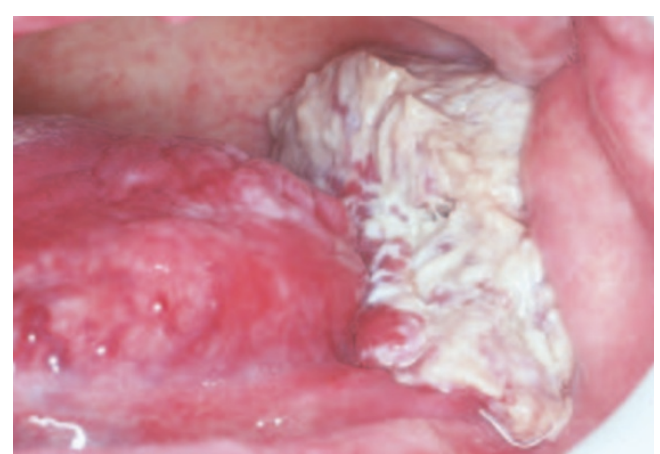

Fig. 8 Squamous cell carcinoma

It is important to note that in patients with OSCC, a second primary neoplasm may be seen elsewhere in the upper aerodigestive tract in up to $25 \%$ over three years. Indeed, many patients treated for OSCC succumb to a second primary

\begin{tabular}{|c|c|}
\hline \multicolumn{2}{|c|}{ Primary tumour size (T) } \\
\hline Tx & No available information \\
\hline T0 & No evidence of primary tumour \\
\hline Tis & Only carcinoma in situ \\
\hline $\mathrm{T} 1, \mathrm{~T} 2, \mathrm{~T} 3, \mathrm{~T} 4$ & Increasing size of tumour ${ }_{b}$ \\
\hline \multicolumn{2}{|c|}{ Regional lymph node involvement (N) } \\
\hline $\mathrm{Nx}$ & Nodes could not or were not assessed \\
\hline No & No clinically positive nodes \\
\hline N1 & $\begin{array}{l}\text { Single clinically positive ipsilateral node less than } 3 \mathrm{~cm} \text { in } \\
\text { diameter }\end{array}$ \\
\hline N2 & $\begin{array}{l}\text { Single clinically positive ipsilateral node } 3 \mathrm{~cm} \text { to } 6 \mathrm{~cm} \text { in } \\
\text { diameter, or multiple clinically positive homolateral nodes, } \\
\text { none more than } 6 \mathrm{~cm} \text { in diameter }\end{array}$ \\
\hline $\mathrm{N} 2 \mathrm{a}$ & $\begin{array}{l}\text { Single clinically positive ipsilateral node } 3 \mathrm{~cm} \text { to } 6 \mathrm{~cm} \text { in } \\
\text { diameter }\end{array}$ \\
\hline $\mathrm{N} 2 \mathrm{~b}$ & $\begin{array}{l}\text { Multiple clinically positive ipsilateral nodes, none more than } \\
6 \mathrm{~cm} \text { in diameter }\end{array}$ \\
\hline N3 & $\begin{array}{l}\text { Massive ipsilateral node(s), bilateral nodes, or contralateral } \\
\text { node(s) }\end{array}$ \\
\hline N3a & $\begin{array}{l}\text { Clinically positive ipsilateral node(s), one more than } 6 \mathrm{~cm} \text { in } \\
\text { diameter }\end{array}$ \\
\hline $\mathrm{N} 3 \mathrm{~b}$ & Bilateral clinically positive nodes \\
\hline N3c & Contralateral clinically positive node(s) \\
\hline \multicolumn{2}{|c|}{ Involvement by distant metastases(M) } \\
\hline $\mathrm{Mx}$ & Distant metastasis was not assessed \\
\hline Mo & No evidence of distant metastasis \\
\hline $\mathrm{M} 1, \mathrm{M} 2, \mathrm{M} 3$ & $\begin{array}{l}\text { Distant metastasis is present. Increasing degrees of metastatic } \\
\text { involvement, including distant nodes }\end{array}$ \\
\hline
\end{tabular}


Fig. 9 Warning features suggestive of carcinoma

\begin{tabular}{|c|c|c|}
\hline Stage & TNM & $\begin{array}{l}\text { Approximate } \% \\
\text { survival at } 5 \text { years }\end{array}$ \\
\hline I & T1 No Mo & 85 \\
\hline II & T2 No Mo & 65 \\
\hline III & $\begin{array}{l}\text { T3 No M0 } \\
\text { T1, T2 or T3 N1 } \\
\text { M0 }\end{array}$ & 40 \\
\hline IV & $\begin{array}{l}\text { Any } 14, N 2, N 3 \\
\text { or M1 }\end{array}$ & 10 \\
\hline
\end{tabular}

\section{WARNING FEATURES}

red lesions (erythroplasia)

a lump

ulcer with fissuring or

raised exophytic

margins

pain or numbness

induration beneath a

lesion, ie a firm

infiltration beneath the

mucosa

voice change

weight loss

tumour rather than a recurrence of the original tumour.

\section{DIAGNOSIS}

Management of early cancers appears to confer survival advantage and is also associated with less morbidity and needs less mutilating surgery. Thus it is important to be suspicious of oral lesions particularly in patients at high risk, such as older males with habits such as the use of tobacco, alcohol or betel, particularly if there is a history of previous OSCC. There should thus be a high index of suspicion, especially of a solitary lesion. Clinicians should be aware that single ulcers, lumps, red patches, or white patches - particularly if any of these are persisting for more than three weeks, may be manifestations of malignancy.

Frank tumours should be inspected and palpated to determine extent of spread; for tumours in the posterior tongue, examination under general anaesthetic by a specialist may facilitate this.

The whole oral mucosa should be examined as there may be widespread dysplastic mucosa ('field change') or even a second neoplasm. The cervical lymph nodes and rest of the upper aerodigestive tract (mouth, nares, pharynx, larynx, oesophagus) must be examined.

\section{Investigations}

It is essential to determine whether bone or muscles are involved or if metastases - initially to regional lymph nodes and later to liver, bone and brain - are present. Imaging may be needed (Figs 10-11). Another important aspect in planning treatment is to determine if there is malignant disease elsewhere, particularly whether other primary tumours are present, and therefore endoscopy may form part of the initial assessment.

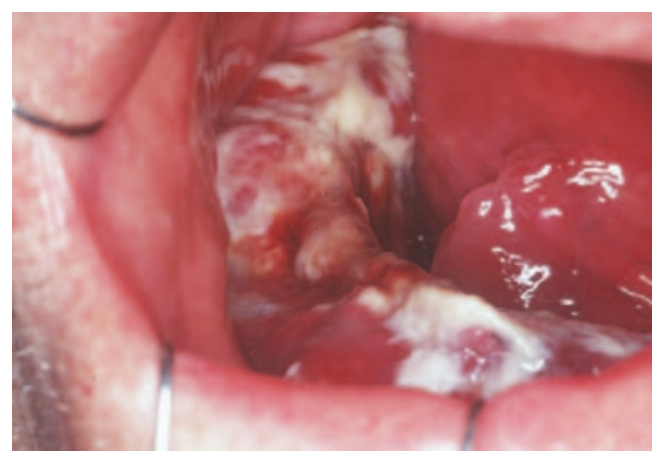

Fig. 10 Squamous cell carcinoma

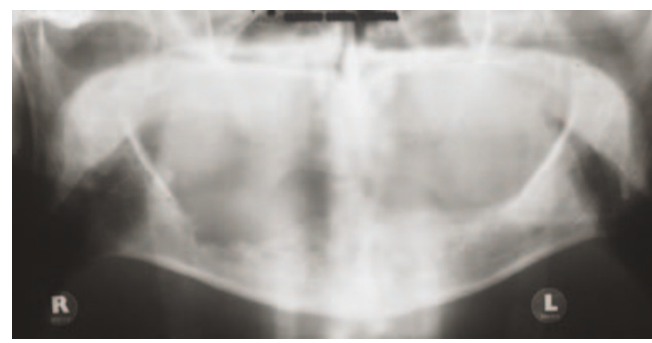

Fig. 11 Radiograph from patient in Fig. 10, showing bony destruction in the mandible

Urgent referral should be made but, if a specialist opinion is not readily accessible, an incisional biopsy can be done in general practice if the practitioner is both competent and confident to carry this out. If you are concerned, phone, email or write for an URGENT specialist opinion which is indicated if you feel a diagnosis of cancer is seriously possible or if the diagnosis is unclear.

One of the most difficult clinical situations in which clinicians find themselves is with the patient in whom cancer is suspected. Patient communication and information are important. If the patient is to be referred to a specialist for a diagnosis and insists (rightly) on a full explanation as to why there is a need for a second opinion, it is probably better to say that you are trained more to be suspicious but hope the lesion is nothing to worry about, though you would be failing in your duty if you did not ask for a second opinion. However, you should leave discussion of actual diagnosis, treatment and prognosis to the specialist concerned, as only they are in a position to give accurate facts regarding future management and prognosis to the patient concerned.

The biopsy should be sufficiently large to include enough suspect tissue to give the pathologist a chance to make a diagnosis and not to have to request a further specimen. Since red rather than white areas are most likely to show dysplasia, a biopsy should be taken of the former. Some authorities always take several biopsies at the first visit in order to avoid the delay, anxiety and aggravation resulting from a negative pathology report in a patient who is strongly suspected as suffering from a malignant neoplasm. Attempts to clinically highlight probable dysplastic areas before biopsy, eg by the use of toluidine blue dye and other vital stains, may be of some help 
where there is widespread 'field change'. Molecular techniques such as DNA ploidy are being introduced for prognostication in potentially malignant lesions and tumours, and to identify nodal metastases.

Finally, the person organising treatment also needs to ensure that the patient is as prepared as possible for the major surgery required, particularly in terms of general anaesthesia, potential blood loss and ability to metabolise drugs, and to address any potential medical, dental or oral problems pre-operatively, to avoid complications. Therefore almost invariably indicated are an assessment of the dentition and periodontum and:

- Medical examination

- Biopsy of equivocal neck lymph nodes

- Jaw and chest radiography

- MRI or CT

- Electrocardiography

- Blood tests.

Selected patients may also need:

- Bronchoscopy - if chest radiography reveals lesions

- Endoscopy - if there is a history of tobacco use

- Gastroscopy - if PEG (per-endoscopic gastrostomy) is to be used for feeding post-surgery

- Liver ultrasound - to exclude metastases

- Doppler duplex flow studies and angiography: to help in planning free flaps for reconstruction.

\section{MANAGEMENT}

Cancer treatment involves a team approach involving a range of specialties including surgeons, anaesthetists, oncologists, nursing staff, dental staff, nutritionists, speech and physiotherapists, and others. Increasingly, Head and
Neck Tumour Boards are being developed along with Cancer Networks to facilitate the collaboration of providers of cancer services to provide seamless care based on best practice (eg http://www.eastman.ucl.ac.uk/hntb/index.html). Consensus guidelines to treatment are now being published.

OSCC is now treated largely by surgery and/or radiotherapy to control the primary tumour and metastases in cervical lymph nodes. Treatment and prognosis are assessed from the TNM classification (Tables 3 and 4).

The planning phase includes discussions regarding restorative and surgical interventions required before cancer treatment, including osseointegrated implants and jaw and occlusal reconstruction. Therapy is also planned to avoid post-operative complications. As much oral care as possible should be completed before starting cancer treatment.

Oral care is especially important when radiotherapy is to be given, since there is a liability particularly to mucositis, xerostomia and other complications, and a risk of osteonecrosis - the initiating factor for which is often trauma, such as tooth extraction, or ulceration from an appliance, or oral infection.

\section{Websites and patient information} http://www.entnet.org/cancer.html http://cancer.med.upenn.edu/new/index.html http://www.oralcancer.org http://www.nlm.nih.gov/medlineplus/oralcancer.html http://www.dh.gov.uk/PolicyAndGuidance/HealthAn dSocialCareTopics/Cancer/fs/en

http://www.mayoclinic.com/invoke.cfm?objectid=F4D66AB7-A46B-46EF-BC71F844B 12

232A0

http://www.rdoc.org.uk/
Patients to refer

All patients with suspected oral malignancy 